\title{
ALKBH5-Induced Demethylation of Mono- and Dimethylated Adenosine
}

Timm T. Ensfelder, $\ddagger^{\mathrm{a}}$ Matthias Q. Kurz, $\ddagger^{\mathrm{a}}$ Katharina Iwan, $\ddagger^{\mathrm{a}}$ Simon Geiger, ${ }^{\text {a }}$ Sarah Matheisl, ${ }^{\mathrm{b}}$ Markus Müller, ${ }^{\mathrm{a}}$ Roland Beckmann, ${ }^{\mathrm{b}}$ Thomas Carell, ${ }^{* a}$

* Corresponding authors

$\ddagger$ Equal contributions

${ }^{a}$ Center for Integrated Protein Science, Department of Chemistry, Ludwig-Maximilians-Universität München, Butenandtstraße 5-13, 81377 Munich, Germany

E-mail: Thomas.carell@Imu.de Web: http://www.carellgroup.de

${ }^{b}$ Gene Center and Department of Biochemistry, Ludwig-Maximilians-Universität München, Feodor-Lynen-Straße 25, 81377 Munich, Germany

The article was first published online in Chemical Communications on 05.07.2018.

Print article: Chem. Commun., 2018,54, 8591-8593

RNA contains methylated A-base derivatives. A methylation to $m^{6} A$ and then demethylation regulate homeostasis in mRNA. It is assumed that $m^{6} A$ is mainly demethylated by the $\alpha$-ketoglutarate dependent oxidase ALKBH5. Here we show that ALKBH5 also demethylates the dimethylated adenosine $\mathrm{m}^{6}{ }_{2} \mathrm{~A}$, which is a non-canonical base present in ribosomal RNA.

RNA contains a large number of modified nucleosides. ${ }^{1,2}$ Most abundant throughout all RNA species are mono-methylated or multiply methylated nucleosides. ${ }^{2}$ Particularly high levels of methylated nucleosides are detected in transfer RNA (tRNA), but also ribosomal RNA (rRNA) and messenger RNA (mRNA) feature such non-canonical nucleosides. ${ }^{1,3}$ Basically, for all canonical nucleosides methylated derivatives exist. ${ }^{1}$ They all serve different functions. ${ }^{4}$ The methylated RNA nucleoside $\mathrm{m}^{6} \mathrm{~A}$ was first reported in mRNA in $1974^{5,6}$ and is among the best studied modifications within the set of methylated adenosines (Fig. 1). ${ }^{7}$

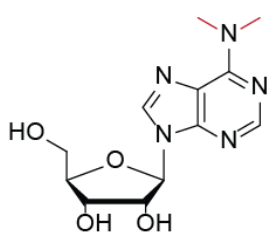

$\mathrm{m}_{2}^{6} \mathrm{~A}$

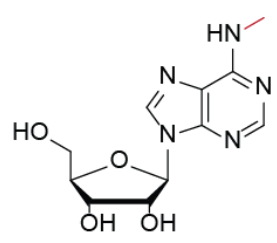

$m^{6} \mathrm{~A}$

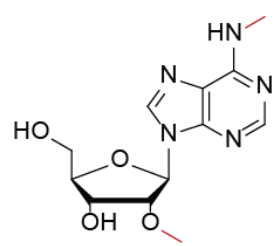

$\mathrm{m}^{6} \mathrm{Am}$

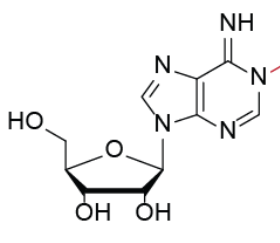

$\mathrm{m}^{1} \mathrm{~A}$

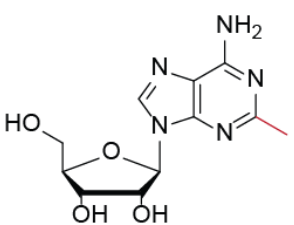

$\mathrm{m}^{2} \mathrm{~A}$

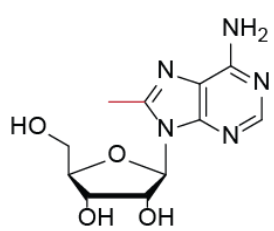

$\mathrm{m}^{8} \mathrm{~A}$

Fig. 1 selection of natural occurring methylated adenosines in RNA.

Others ${ }^{8-14}$ and we $\mathrm{e}^{15}$ have shown that the nucleoside recruits and repels proteins to control the lifetime of the corresponding mRNA. As such the nucleoside is directly involved in regulating mRNA homeostasis. ${ }^{15}$ Particularly exciting is the observation that the nucleoside $\mathrm{m}^{6} \mathrm{~A}$ can be demethylated by $\alpha$-ketoglutarate dependent oxidases, ${ }^{16}$ which opens the possibility that methylation and demethylation establish a new layer of regulation to facilitate transcriptional control. In addition to $\mathrm{m}^{6} \mathrm{~A}$, ribosomal RNA also contains the double methylated species $\mathrm{m}_{2}^{6} \mathrm{~A}$, where two methyl groups are both situated at the exocyclic $N^{6}$-heteroatom. Because the methyl groups are connected to a heteroatom, this oxidation would allow oxidative double demethylation of $\mathrm{m}^{6} \mathrm{~A}$ in contrast to $\mathrm{m}^{2} \mathrm{~A}$ and $\mathrm{m}^{8} \mathrm{~A}$, where the methyl group resides on a carbon. Such sequential demethylations performed by a single enzyme are known: for example, histone demethylases are able to demethylate mono-, di- and even trimethylated lysines. ${ }^{17,18}$ Here, we investigated if the $\mathrm{Fe}^{2+}-, \alpha$-ketoglutarate-dependent ALKBH5, which is known to demethylate $\mathrm{m}^{6} \mathrm{~A}$, would be able to demethylate naturally occurring $\mathrm{m}^{6} \mathrm{~A}$ as well. In contrast to $\mathrm{m}^{6} \mathrm{~A}$, however, $\mathrm{m}^{6}{ }_{2} \mathrm{~A}$ is predominately, if not exclusively, found in a conserved sequence context of the small ribosomal subunit. ${ }^{2,3}$ For this study, we first investigated the demethylation of small RNA strands containing $\mathrm{m}^{6} \mathrm{~A}$ and $\mathrm{m}^{6}{ }_{2} \mathrm{~A}$ in different sequence contexts with ALKBH5 $5_{66-292}$ in vitro. Therefore, we synthesized the 
phosphoramidites of $\mathrm{m}^{6} \mathrm{~A}$ and $\mathrm{m}^{6}{ }_{2} \mathrm{~A}$ and subsequently used them for solid phase RNA synthesis (SPOS) of oligoribonucleotides (ORN) 1-4 (Fig. 2). In this study we inserted $m^{6} A$ and $m^{6}{ }_{2} A$ into their natural sequence context, i.e., $5^{\prime}-G G m^{6} A C U-3^{\prime}$ for $m^{6} A$ and $5^{\prime}$ GUGm ${ }_{2}^{6} A-m^{6}{ }_{2} A C U U-3^{\prime}$ for $m^{6}{ }_{2} A$. To address potential sequence bias during the enzymatic studies, we also inserted $m^{6} A$ into the sequence of $\mathrm{m}^{6}{ }_{2} \mathrm{~A}$ and vice versa. In addition to the investigation with pure oligonucleotides, the study was furthermore complemented with the putative demethylation of $\mathrm{m}^{6}{ }_{2} \mathrm{~A}$ in intact ribosomes and in human ribosomal rRNA.

The $\mathrm{His}_{6}$-tagged protein human ALKBH566-292 enzyme was overexpressed in E. coli BL21(DE3) from a pNIC28-Bsa4-ALKBH566-292 plasmid $^{19}$ using a modified procedure compared to the literature ${ }^{20}$ data (see the ESI) and isolated in one step via Ni-NTA affinity chromatography. This procedure yielded the protein in a purity of $90 \%$ (ESI, Fig. S1). The buffer was changed to the assay buffer $(50 \mathrm{mM}$ Tris $\mathrm{HCl}, \mathrm{pH} 7.5,15 \mathrm{mM} \mathrm{KCl}$ ). Stock solutions of diammonium-Fe(ii)-sulfate and $\alpha$-ketoglutarate were prepared fresh for every assay and added to a final concentration of $300 \mu \mathrm{M}$. ALKBH5 $5_{66-292}$ concentrations in the assay buffer were either 10 or 16 $\mu \mathrm{M}$. The corresponding oligonucleotides were held constant at $10 \mu \mathrm{M}$. Exclusion of oxygen was not needed. The solution was incubated at $37{ }^{\circ} \mathrm{C}$ for about $1 \mathrm{~h}$ (see the ESI). For analysing the demethylation reaction, we desalted the assay solution using a Millipore MF ${ }^{\mathrm{TM}}$ VSWP-membrane $(0.025 \mu \mathrm{m})$ and measured the molecular weight of the oligonucleotides using MALDI-TOF mass spectrometry. The obtained data are depicted in Fig. 2.
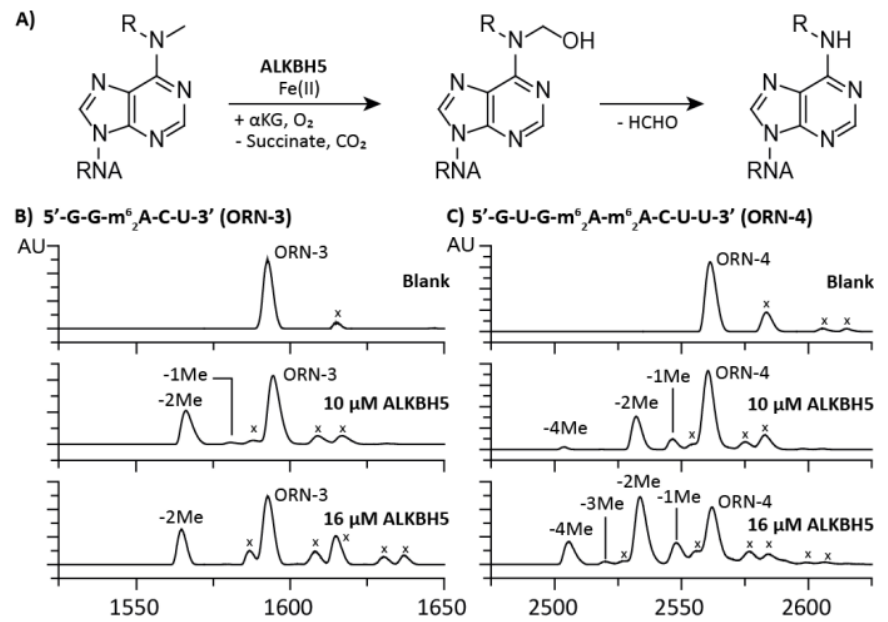

D)

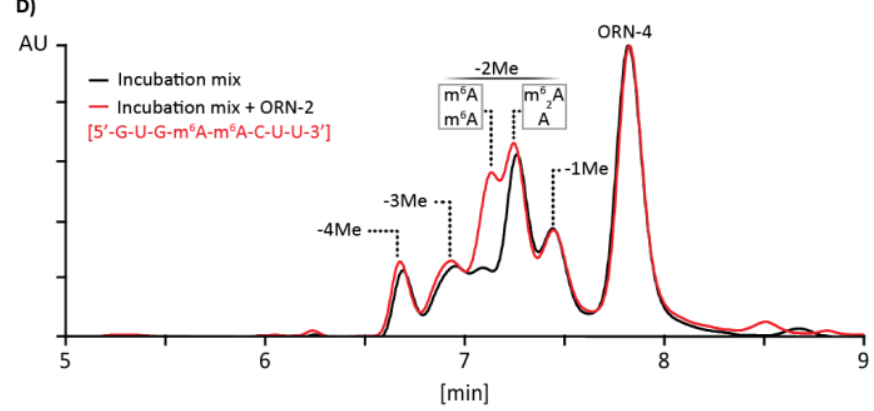

Fig. 2 (A) Oxidation scheme of methylated adenine by ALKBH5 with R being a hydrogen or methyl group. (B-C) MALDI-ToF spectra of the ORN 3-4 and their demethylation products (-xMe) at different concentrations of ALKBH5 $5_{66-292}$. The sodium signals in the spectra are marked with an " $\mathrm{H}$ ". (D) HPL chromatogram of the incubation of ORN4 with $16 \mu \mathrm{M} \mathrm{ALKBH} 5_{66-292}$ (black line) and with a spike in of ORN-2 (red line).

As expected, we observed complete demethylation of $\mathrm{m}^{6} \mathrm{~A}$ in both sequence contexts ORN-1 and ORN-2 (ESI, Fig. S2A and B). This is interesting because it shows that the oxidation of $\mathrm{m}^{6} \mathrm{~A}$, putatively to the corresponding $N^{6}$-hydroxymethyl-A followed by hydrolysis of the hemiaminal (Fig. 2A), has no observable sequence bias under our conditions. In addition, we see that the demethylation proceeds also at two directly adjacent $\mathrm{m}^{6} \mathrm{~A}$ to completion. When we analysed the demethylation with the $\mathrm{m}_{2}{ }_{2} \mathrm{~A}$ strands ORN-3 and ORN-4 (Fig. 2B and C), we obtained more complex spectra. We could indeed detect demethylation but with a significantly reduced efficiency. When $\mathrm{m}^{6} \mathrm{~A}$ is placed in the context of the $\mathrm{m}^{6} \mathrm{~A}$ consensus sequence, the formation of the monodemethylated ORN-3 at $10 \mu \mathrm{M}$ enzyme concentration is seen, furthermore the fully demethylated ORN-3 (-2Me) is clearly visible (Fig. 2B). The conversion is about 40\%, estimated based on the observed signal intensities. Demethylation in the rRNA context, where two directly adjacent $\mathrm{m}^{6}{ }_{2} \mathrm{~A}$ occur, is shown in Fig. 2C. At $10 \mu \mathrm{M}$ and an incubation time of $1 \mathrm{~h}$, mono-, di-, and tetrademethylations are observed. At a slightly higher enzyme concentration, we detected all expected species with the loss of onefour methyl groups. The loss of two methyl groups can yield two different species, either one with $m^{6} A-m^{6} A$ or one with $m^{6}{ }_{2} A-A$. To address this issue, we further performed LC-MS analysis of the ORN-4 assay mixture with and without a spike of ORN-2. Fig. 2D shows that both species occur and the $\mathrm{m}^{6}{ }_{2} \mathrm{~A}-\mathrm{A}$ product is the favoured one. In summary, the data show that ALKBH5 ${ }_{66-292}$ is able to fully demethylate an $m^{6}{ }_{2} A-m^{6}{ }_{2} A$ sequence via oxidation of all four methyl groups. Interestingly, the mono-and tri-demethylated 
ORNs do not accumulate. We interpret this effect as an indication that the first demethylation step is rate limiting, while the demethylation of $\mathrm{m}^{6} \mathrm{~A}$ proceeds quickly.

A)

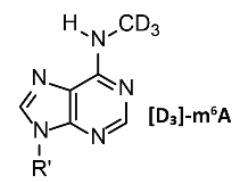

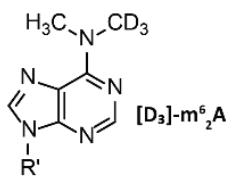

B)
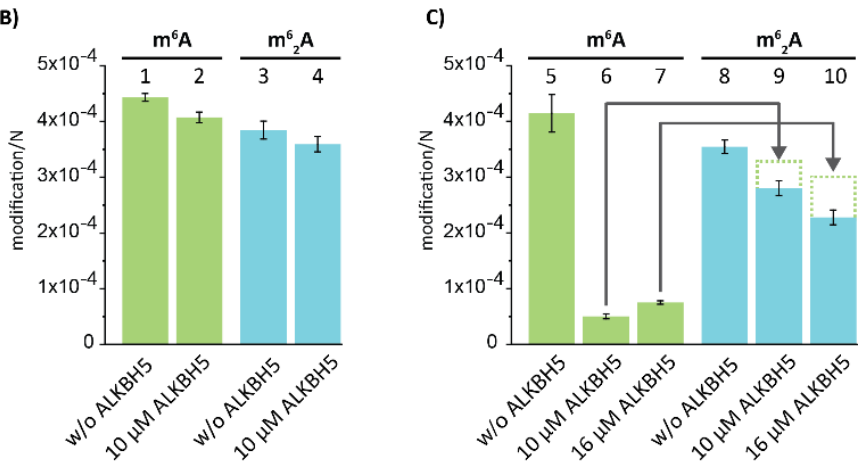

Fig.3 Quantification data of $\mathrm{m}^{6} \mathrm{~A}$ and $\mathrm{m}_{2}^{6} \mathrm{~A}$ upon incubation with $\mathrm{ALKBH} 5_{66-292}$ in different concentrations. (A) For quantification isotope labelled standards of $\mathrm{m}^{6} \mathrm{~A}$ and $m^{6}{ }_{2} A$ were used. $R^{\prime}$ represents ribose sugar moiety. (B) Represents the amount in ribosomes and (C) the amount in rRNA. The dashed lines shown in (C) indicate that the sum of residual $\mathrm{m}^{6} \mathrm{~A}$ and $\mathrm{m}^{6} \mathrm{~A}$.

We next wanted to study if double-demethylation of $\mathrm{m}^{6}{ }_{2} \mathrm{~A}$ is also possible on intact rRNA. To this end, we isolated the ribosomes from HEK293T cells using ultracentrifugation followed by rRNA isolation. The obtained ribosomes and rRNA are more complex than the synthesized oligonucleotides because they contain one $m^{6} A$ per subunit and in addition the $m^{6}{ }_{2} A-m^{6}{ }_{2} A$ sequence. These $\mathrm{m}^{6}{ }_{2} \mathrm{~A}$ positions are highly conserved in all species with only very few exceptions. ${ }^{21}$ For the analysis, due to the large size of the RNA strand, we digested the RNA after the assay to the individual nucleosides and measured all four canonical nucleosides plus the methylated adenosines $\mathrm{m}^{6} \mathrm{~A}$ and $\mathrm{m}^{6}{ }_{2} \mathrm{~A}$ via UHPLC-MS/MS using our described procedure (see the ESI). In order to obtain absolute quantitative data, we synthesized the isotopologues of $\mathrm{m}^{6} \mathrm{~A}$ and $\mathrm{m}^{6}{ }_{2} \mathrm{~A}$ that were used for internal calibration (see the ESI). The obtained quantitative MS-data are compiled in Fig. 3. In the control studies performed without enzymes, we clearly detected the $\mathrm{m}^{6} \mathrm{~A}$ and $\mathrm{m}^{6}{ }_{2} \mathrm{~A}$ nucleosides at the expected ratios (two of each per rRNA). Upon addition of ALKBH5 $66-292$ in two different concentrations, we see a clear and strong reduction of the $\mathrm{m}^{6} \mathrm{~A}$ signal, showing that in principle $\mathrm{ALKBH} 5_{66-292}$ is able to demethylate $\mathrm{m}^{6} \mathrm{~A}$ also in ribosomal RNA. Because the sequence context is different, this result argues again that the activity of ALKBH5 ${ }_{66-292}$ has no observable sequence preference. One has to note that in these experiments ALKBH5 $5_{66-292}$ is present in great excess over the used large rRNA. Interestingly, however, $\mathrm{m}^{6} \mathrm{~A}$ levels are not reduced to zero which we would expect based on the observed full demethylation with the smaller RNA strands. For $\mathrm{m}^{6}{ }_{2} \mathrm{~A}$, we also see clearly reduced levels, showing that ALKBH5 $5_{66-292}$ demethylated $\mathrm{m}^{6}{ }_{2} \mathrm{~A}$ also in rRNA. It is interesting to note that at $16 \mu \mathrm{M}$ enzyme concentration, in contrast to the ORN, the resulting m ${ }^{6} \mathrm{~A}$ values are higher than those observed at $10 \mu \mathrm{M}$, despite lower $\mathrm{m}^{6}{ }_{2} \mathrm{~A}$ levels. We hypothesize that the observed $\mathrm{m}^{6} \mathrm{~A}$ levels are the hemidemethylated intermediates that are obtained when ALKBH5 $5_{66-292}$ oxidizes and demethylates $m^{6}{ }_{2} A$. The sum of residual $m^{6} A$ and $\mathrm{m}^{6}{ }_{2} A$ levels never exceeds the starting values of $\mathrm{m}^{6}{ }_{2} \mathrm{~A}$ (Fig. 3D), showing that the full demethylation of $\mathrm{m}^{6}{ }_{2} \mathrm{~A}$ occurs and that all the original $\mathrm{m}^{6} \mathrm{~A}$ was likely demethylated as well.

\section{Conclusions}

ALKBH5 is an $\alpha$-ketoglutarate-dependent oxidase that was shown to demethylate $m^{6} \mathrm{~A}$ in mRNA. We investigated here if the enzyme is able to demethylate also the double-methylated $m^{6}{ }_{2} A$, which is known to occur in the small subunit of the ribosome. We also wanted to know if the enzyme is in addition able to demethylate $m^{6} \mathrm{~A}$ in rRNA. We show that ALKBH5 demethylates $\mathrm{m}^{6} \mathrm{~A}$ in basically all sequence contexts, when used at an equimolar ratio or higher, even when two $\mathrm{m}^{6} \mathrm{~A}$ bases are adjacent to each other. It also demethylates $\mathrm{m}^{6}{ }_{2} \mathrm{~A}$ both in rRNA and in small ORNs. Here, in general demethylation occurs and the monodemethylated intermediate (ORN3/ORN4 -1Me; Fig. 2D and E) is detectable. This is very interesting because it shows that the enzyme releases its substrate after the first demethylation step. Since the demethylation of the mono-methylated compound $\mathrm{m}^{6} \mathrm{~A}$ is much more efficient compared to $\mathrm{m}^{6}{ }_{2} \mathrm{~A}$, one would expect direct conversion of $\mathrm{m}^{6} \mathrm{~A}$ into adenosine if the substrate is not released. We speculate that the substrate release after the first demethylation could be required to reload another $\alpha$-ketoglutarate co-substrate into the active site. It is unclear if the demethylation of $\mathrm{m}_{2}^{6} \mathrm{~A} A L K B H 5_{66-292}$ is a process that occurs in nature. We suspect that the small amount of observed demethylation at approximately 100 -fold excess of the enzyme relative to the added rRNA speaks against this possibility. Indeed, when we performed the demethylation studies with assembled ribosomes, demethylation did not occur. This makes demethylation of intact ribosomes unlikely, but it still leaves the possibility that demethylation occurs during rRNA maturation similar to the insertion of non-canonical nucleosides into mRNA upon mRNA maturation. 


\section{Acknowledgements}

We thank Felix Hagelskamp and the Kellner Lab (LMU Munich) for sharing unpublished protocols. We thank Christina Schneider for applying this protocol to help us with the LC-MS measurements. We thank Michael McDonough, Christopher Schofield and Dong Zhang for kindly providing us with the pNIC28-Bsa4-ALKBH5 ${ }_{66-292}$ plasmid. Furthermore, we thank the Deutsche Forschungsgemeinschaft (SFB749, SFB1032, GRK2062 and SPP1784) for financial support. Additional support was obtained from the Excellence Cluster CIPSM.

\section{Conflicts of interest}

There are no conflicts to declare.

\section{Notes and references}

1. P. Boccaletto, M. A. Machnicka, E. Purta, P. Piątkowski, B. Bagiński, T. K. Wirecki, V. de Crécy-Lagard, R. Ross, P. A. Limbach, A. Kotter, M. Helm and J. M. Bujnicki, Nucleic Acids Res., 2018, 46, D303-D307.

2. M. A. Machnicka, K. Milanowska, O. Osman Oglou, E. Purta, M. Kurkowska, A. Olchowik, W. Januszewski, S. Kalinowski, S. Dunin-Horkawicz, K. M. Rother, M. Helm, J. M. Bujnicki and H. Grosjean, Nucleic Acids Res., 2013, 41, D262-267.

3. D. Piekna-Przybylska, W. A. Decatur and M. J. Fournier, Nucleic Acids Res., 2008, 36, D178-183.

4. G. Jia, Y. Fu and C. He, Trends Genet., 2013, 29, 108-115.

5. R. Desrosiers, K. Friderici and F. Rottman, Proc. Natl. Acad. Sci. U. S. A., 1974, 71, 3971-3975.

6. R. P. Perry and D. E. Kelley, Cell, 1974, 1, 37-42.

7. B. S. Zhao, I. A. Roundtree and C. He, Nat. Rev. Mol. Cell Biol., 2016, 18, 31-42.

8. W. Xiao, S. Adhikari, U. Dahal, Y.-S. Chen, Y.-J. Hao, B.-F. Sun, H.-Y. Sun, A. Li, X.-L. Ping, W.-Y. Lai, X. Wang, H.-L. Ma, C.M. Huang, Y. Yang, N. Huang, G.-B. Jiang, H.-L. Wang, Q. Zhou, X.-J. Wang, Y.-L. Zhao and Y.-G. Yang, Mol. Cell, 2016, 61, 507-519.

9. D. P. Patil, C.-K. Chen, B. F. Pickering, A. Chow, C. Jackson, M. Guttman and S. R. Jaffrey, Nature, 2016, 537, 369-373.

10. X. Wang, Boxuan S. Zhao, Ian A. Roundtree, Z. Lu, D. Han, H. Ma, X. Weng, K. Chen, H. Shi and C. He, Cell, 2015, 161, 13881399.

11. Kate D. Meyer, Deepak P. Patil, J. Zhou, A. Zinoviev, Maxim A. Skabkin, O. Elemento, Tatyana V. Pestova, S.-B. Qian and Samie R. Jaffrey, Cell, 2015, 163, 999-1010.

12. X. Wang, Z. Lu, A. Gomez, G. C. Hon, Y. Yue, D. Han, Y. Fu, M. Parisien, Q. Dai, G. Jia, B. Ren, T. Pan and C. He, Nature, 2014, 505, 117-120.

13. Kate D. Meyer, Y. Saletore, P. Zumbo, O. Elemento, Christopher E. Mason and Samie R. Jaffrey, Cell, 2012, 149, 16351646.

14. D. Dominissini, S. Moshitch-Moshkovitz, S. Schwartz, M. Salmon-Divon, L. Ungar, S. Osenberg, K. Cesarkas, J. Jacob-Hirsch, N. Amariglio, M. Kupiec, R. Sorek and G. Rechavi, Nature, 2012, 485, 201-206.

15. R. R. Edupuganti, S. Geiger, R. G. H. Lindeboom, H. Shi, P. J. Hsu, Z. Lu, S.-Y. Wang, M. P. A. Baltissen, P. W. T. C. Jansen, M. Rossa, M. Müller, H. G. Stunnenberg, C. He, T. Carell and M. Vermeulen, Nat. Struct. Mol. Biol., 2017, 24, 870-878.

16. G. Zheng, John A. Dahl, Y. Niu, P. Fedorcsak, C.-M. Huang, Charles J. Li, Cathrine B. Vågb $\varnothing$, Y. Shi, W.-L. Wang, S.-H. Song, Z. Lu, Ralph P. G. Bosmans, Q. Dai, Y.-J. Hao, X. Yang, W.-M. Zhao, W.-M. Tong, X.-J. Wang, F. Bogdan, K. Furu, Y. Fu, G. Jia, X. Zhao, J. Liu, Hans E. Krokan, A. Klungland, Y.-G. Yang and C. He, Mol. Cell, 2013, 49, 18-29.

17. K. Yamane, C. Toumazou, Y.-i. Tsukada, H. Erdjument-Bromage, P. Tempst, J. Wong and Y. Zhang, Cell, 2006, 125, 483495.

18. S. M. Kooistra and K. Helin, Nat. Rev. Mol. Cell Biol., 2012, 13, 297-311.

19. W. Aik, J. S. Scotti, H. Choi, L. Gong, M. Demetriades, C. J. Schofield and M. A. McDonough, Nucleic Acids Res., 2014, 42, 4741-4754.

20. F. W. Studier, Protein Expression Purif., 2005, 41, 207-234.

21. Z. Xu, H. C. O'Farrell, J. P. Rife and G. M. Culver, Nat. Struct. Mol. Biol., 2008, 15, 534-536. 


\section{ALKBH5-Induced Demethylation of Mono- and Dimethylated Adenosine}

Timm T. Ensfelder, $\ddagger^{\mathrm{a}}$ Matthias Q. Kurz, $\ddagger^{\mathrm{a}}$ Katharina Iwan, $\ddagger^{\mathrm{a}}$ Simon Geiger, ${ }^{\mathrm{a}}$ Sarah Matheisl, ${ }^{\mathrm{b}}$ Markus Müller, ${ }^{\text {a }}$ Roland Beckmann, ${ }^{\mathrm{b}}$ Thomas Carell, ${ }^{* a}$

Center for Integrated Protein Science (CiPS ${ }^{\mathrm{M}}$ ) at the Department of Chemistry, LudwigMaximilians-Universität München, Butenandtstrasse 5-13, 81377 Munich.

Gene Center and Department of Biochemistry, Ludwig-Maximilians-Universität München, Feodor-Lynen-Straße 25, 81377 Munich.

E-mail:Thomas.Carell@cup.uni-muenchen.de 


\section{Index}

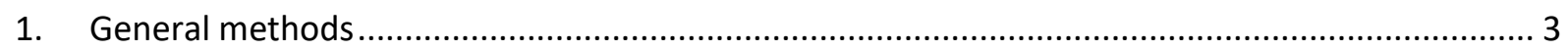

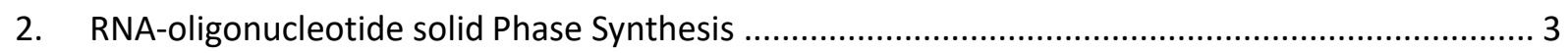

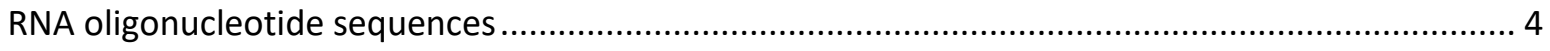

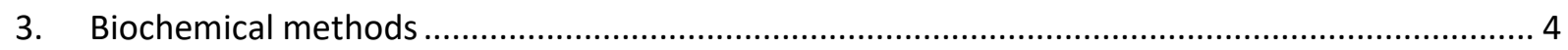

Ribosome isolation by Ultracentrifugation and rRNA isolation ................................................. 4

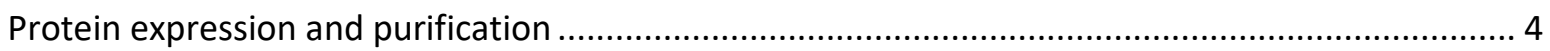

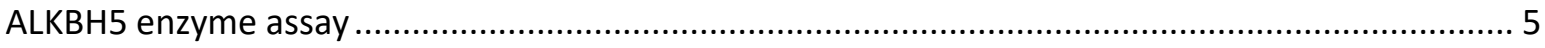

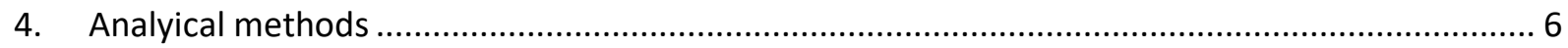

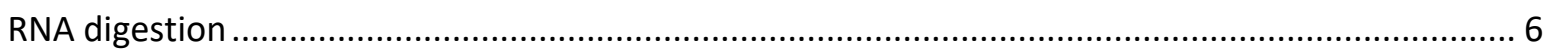

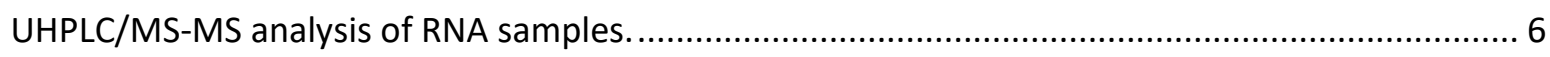

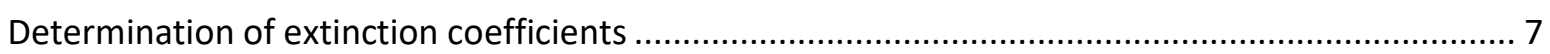

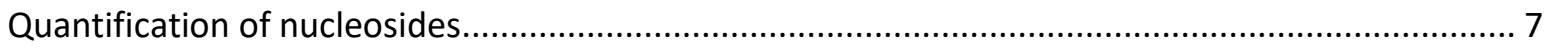

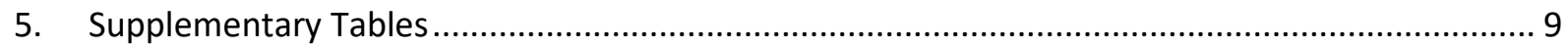

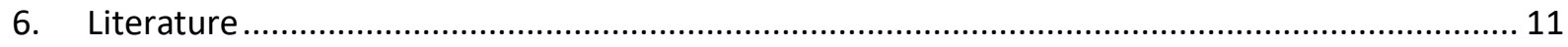




\section{General methods}

Acetonitrile for HPLC-purification of nucleoside standards and oligonucleotides were purchased from VWR. Triethylamine and acetic acid (glacial) for HPLC buffer preparation was purchased from SigmaAldrich resp. from Fisher Scientific. Water of LC-MS grade was purchased from Honeywell. Acetonitrile of LC-MS grade was purchased from Carl Roth $\mathrm{GmbH}+\mathrm{Co}$. KG. Formic acid was purchased from Fluka, p.a. for mass spectrometry. Water was purified by an arium ${ }^{\circledR}$ pro DI Ultrapure Water System from Satorius Stedim biotech. Nuclease S1 (Aspergillus oryzae) was obtained from Sigma Aldrich, snake venom phosphodiesterase I (Crotalus adamanteus) from USB corporation and antarctic phosphatase from New England Biolabs.

\section{RNA-oligonucleotide solid Phase Synthesis}

The phosphoramidites of $\mathrm{m}^{6} \mathrm{~A}$ and $\mathrm{m}^{6} \mathrm{~A}$ were synthesised according to literature ${ }^{1,2}$

The $\mathrm{m}^{6} \mathrm{~A}$ and $\mathrm{m}^{6}{ }_{2} \mathrm{~A}$ containing RNA oligonucleotides were synthesised on an ABI 394 DNA/RNA Synthesizer (Applied Biosystems) using typical reagent concentrations [detritylation: 3\% dichloroacetic acid in DCM (emp biotech), activator: $0.3 \mathrm{M}$ benzylthiotetrazole in MeCN (Link Technoligies), capping: Capping A (ABI) \& Capping B (ABI) solution (J.T. Baker), oxidation: Oxidizing (ABI) solution (J.T. Baker)]. The oligonucleotide synthesis were carried out on $1 \mu \mathrm{mol}$ scale with CPG carriers (SynBase CPG 1000/110) and 0.1 M solutions in MeCN of TBDMS-protected standard RNA phosphoramidites (U, $\mathrm{dmf}-\mathrm{G}, \mathrm{Ac}-\mathrm{C}$ and $\mathrm{Bz}-\mathrm{A}$ ) obtained from Link Technologies. Both modified phosphoramidites, $\mathrm{m}^{6} \mathrm{~A}$ and $\mathrm{m}^{6}{ }_{2} \mathrm{~A}$ were incorporated into RNA using the standard protocol but the coupling times were increased to $20 \mathrm{~min}$.

After synthesis, the CPG material from the cartridges were treated with $1 \mathrm{~mL}$ of AMA solution (28\% $\mathrm{NH}_{4} \mathrm{OH}$ in $\mathrm{H}_{2} \mathrm{O} / 40 \% \mathrm{MeNH}_{2}$ in $\mathrm{H}_{2} \mathrm{O}, 1: 1$ ) first at room temperature for 5 min and secondly at $65^{\circ} \mathrm{C}$ for $5 \mathrm{~min}$ to ensure complete cleavage of the oligonucleotide from the resin and basic deprotection. The AMA solution was removed in vacuo. The residue was dissolved in DMSO $(100 \mu \mathrm{L})$ and $\mathrm{Et}_{3} \mathrm{~N} \cdot 3 \mathrm{HF}$ was added and the mixture was heated to $65{ }^{\circ} \mathrm{C}$ for $90 \mathrm{~min}$. After the addition of a NaOAc solution ( $3 \mathrm{M}, \mathrm{pH}=5.5,25 \mu \mathrm{L}$ ) the oligonucleotides were precipitated by addition of $n-\mathrm{BuOH}(1 \mathrm{~mL})$ and cooling to $-80{ }^{\circ} \mathrm{C}$ for $12 \mathrm{~h}$. The suspension was centrifuged at $4{ }^{\circ} \mathrm{C}$ with $21130 \mathrm{x} \mathrm{g}$ for $60 \mathrm{~min}$ to pelletise the crude oligonucleotides. Further purification and analysis of the final product was performed on a Waters HPLC system (preparative HPLC: 1525 with 2487 UV detector, analytical HPLC: Waters Alliance 2695 with PDA 2996) with Nucleodur C-18 Columns from Macherey Nagel. The used gradient was $0.1 \mathrm{M}$ Triethylammonium actetate in water and $80 \% \mathrm{MeCN}$. The purified oligonucleotides were 
desalted using Sep-Pak C18 Classic Cartridges (Waters) before further usage and the identity was confirmed by MALDI-ToF-MS.

\section{RNA oligonucleotide sequences}

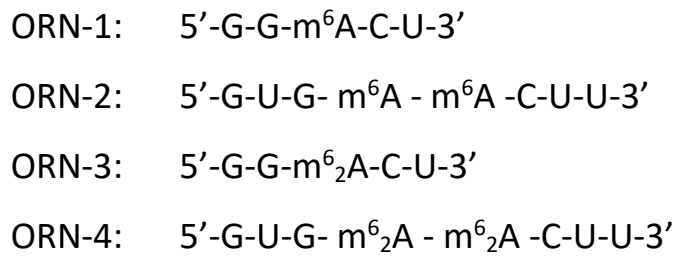

\section{Biochemical methods}

\section{Ribosome isolation by Ultracentrifugation and rRNA isolation}

Native ribosomes were isolated from pelleted HEK $293 \mathrm{~T}$ cells. $10 \cdot 10^{7}$ cells were resuspended in $6 \mathrm{~mL}$ of lysis buffer $(50 \mathrm{mM}$ Tris. $\mathrm{HCl}$ pH 7.5, $300 \mathrm{mM} \mathrm{NaCl}, 6 \mathrm{mM} \mathrm{MgCl}$, $0.5 \% \mathrm{NP}-40$ Substitute, $0.2 \mathrm{U} / \mu \mathrm{L}$ RNasin). Lysis was performed by incubating the cells in lysis buffer for $30 \mathrm{~min}$ at $4{ }^{\circ} \mathrm{C}$. Cell debris was removed by centrifugation (Eppendorf FA-45-24-11 rotor, $5 \mathrm{~min}, 12000 \times \mathrm{g}, 4^{\circ} \mathrm{C}$ ). The supernatant was than incubated with a final Puromycin concentration of $1 \mathrm{mM}$ for $15 \mathrm{~min}$ at RT and another $15 \mathrm{~min}$ at $4{ }^{\circ} \mathrm{C}$. After the incubation the supernatant was loaded on sucrose cushion buffer $(50 \mathrm{mM}$ Tris. $\mathrm{HCl}$ $\mathrm{pH}$ 7.5, $300 \mathrm{mM} \mathrm{NaCl}, 6 \mathrm{mM} \mathrm{MgCl}$, 30\% (w/v) sucrose, $0.2 \mathrm{U} / \mu \mathrm{L}$ RNasin). The ribosomes were pelleted by centrifuging for $15 \mathrm{~h} 30 \mathrm{~min}$ (Beckman Coulter TLA 120.2, $24001 \mathrm{x} \mathrm{g}, 4^{\circ} \mathrm{C}$ ).

The supernatant was removed. The pellet was resuspended in resuspension buffer ( $50 \mathrm{mM}$ Tris· $\mathrm{HCl}$ $\mathrm{pH} 7.5,150 \mathrm{mM} \mathrm{NaCl}, 6 \mathrm{mM} \mathrm{MgCl} 2,3.48 \%$ (w/v) sucrose) over a time of $2 \mathrm{~h}$ on ice. Any possible impurity was removed by another centrifugation (Eppendorf FA-45-24-11 rotor, $1 \mathrm{~min}, 12000 \times \mathrm{g}, 4^{\circ} \mathrm{C}$ ). The ribosome concentration was determined by measuring the $A_{260}$. The rRNA was isolated from the ribosome solution using the Monarch ${ }^{\circledR}$ Total RNA Miniprep Kit by NEB according to its protocol.

\section{Protein expression and purification}

A pNIC28-Bsa4 vector which is encoding an $\mathrm{N}$-terminal $\mathrm{His}_{6}$-tagged $\mathrm{ALKBH}_{66-292}$, was transformed into Escherichia coli BL21 (DE3). Expression was performed in ZYM-5052 auto induction medium without trace metals, for $3 \mathrm{~h}$ at $37^{\circ} \mathrm{C}$ and $17 \mathrm{~h}$ to $20 \mathrm{~h}$ at $20^{\circ} \mathrm{C}$ and $300 \mathrm{rpm}$. The cells were harvested by centrifugation (Thermo Fisher Scientific Fiberlite ${ }^{\mathrm{TM}} \mathrm{F} 10-4 \times 1000$ LEX rotor, 11970 x g, $4{ }^{\circ} \mathrm{C}, 8 \mathrm{~min}$ ) and stored at $-20^{\circ} \mathrm{C}$. A ratio of 10:1 ( $1 \mathrm{~mL}$ buffer per $0.1 \mathrm{~g}$ pellet) was used to resuspend the cell pellet in lysis buffer (50 mM Tris. $\mathrm{HCl} \mathrm{pH} \mathrm{7.5,} 150 \mathrm{mM} \mathrm{KCl}, 10 \mathrm{mM}$ Imidazol). Furthermore cOmplete ${ }^{\mathrm{TM}}$ EDTA free protease inhibitor (Sigma-Aldrich) and Lysozyme were added. After an incubation of 30 min on ice, the cells were lysed by sonification on ice. The cell debris was removed by centrifugation (Thermo Fisher Scientific Sorvall SS-34 rotor, $38720 \times \mathrm{g}, 4^{\circ} \mathrm{C}, 30 \mathrm{~min}$ ). The lysate was filtered and applied to a HisTrap HP ( $5 \mathrm{~mL}$ ) by GE Healthcare. To remove unspecific binding proteins the column was washed with $8 \%$ 
elution buffer ( $50 \mathrm{mM}$ Tris. $\mathrm{HCl} \mathrm{pH} \mathrm{7.5,150} \mathrm{mM} \mathrm{KCl,} 365 \mathrm{mM}$ imidazole). Elution was performed with a step gradient over ten column volumes. Purification was evaluated with a 15\% SDS-PAGE (Marker Thermo Scientific PageRuler Unstained Protein Ladder \#26614). On average the purity was at $90 \%$ after

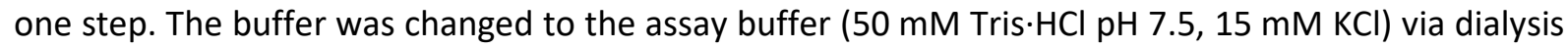
overnight. After dialysis the enzyme solution was centrifuged for $5 \mathrm{~min}$ at $21130 \mathrm{xg}$ and $4{ }^{\circ} \mathrm{C}$ to remove precipitated protein. The enzyme concentration was evaluated with Bradford.

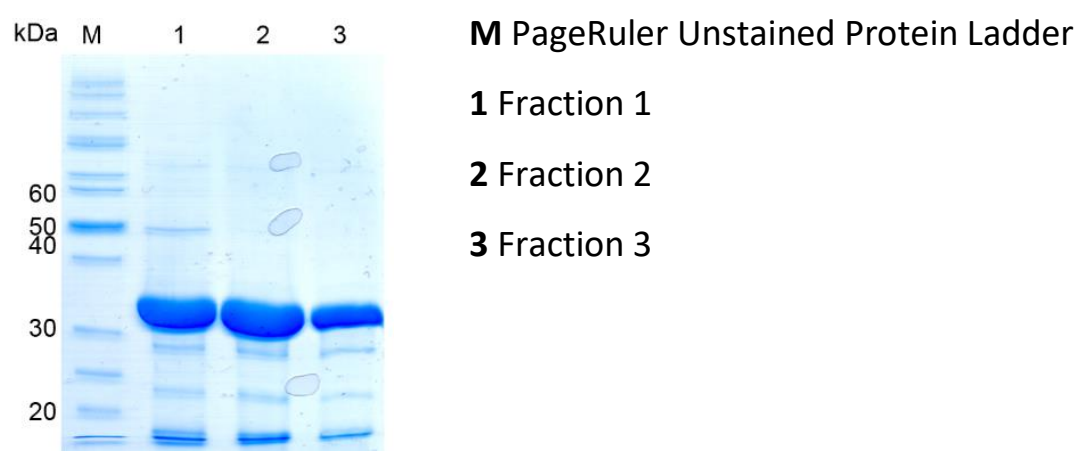

Supplementary Figure 1 ALKBH5 after one purification step. Fraction 2 was used for the enzyme assay with ORN-1 to ORN-4. Estimated purity is $90 \%$.

\section{ALKBH5 enzyme assay}

ALKBH5 $5_{66-292}$ was always used directly without freezing it for storage. Every assay was performed in a volume of $50 \mu \mathrm{L}$ and as a triplicate. Only the assay with rRNA and $16 \mu \mathrm{M}$ ALKBH5 were performed as a duplicate. The final assay mixture was $50 \mathrm{mM}$ Tris. $\mathrm{HCl} \mathrm{pH} \mathrm{7.5,} 15 \mathrm{mM} \mathrm{KCl}, 2 \mathrm{mM} \mathrm{L}$-ascorbate, $300 \mu \mathrm{M}$ $\alpha$-ketoglutarate, $300 \mu \mathrm{M}$ diammonium iron(II) sulfate hexahydrate complex. Assays with native ribosomes did contain $150 \mathrm{mM} \mathrm{KCl}$ instead of $15 \mathrm{mM}$ and also contain sucrose and $\mathrm{MgCl}_{2}$ with a final concentration of $3.48 \%(\mathrm{w} / \mathrm{v})$ and $6 \mathrm{mM}$. In all assays with rRNA, a murine RNase inhibitor was added with a final concentration of $1 \mathrm{U} / \mu \mathrm{L}$. The L-ascorbate, $\alpha$-ketoglutarate and diammonium iron(II) sulfate hexahydrate solutions were made afresh. The concentration of the synthetic RNA oligonucleotides

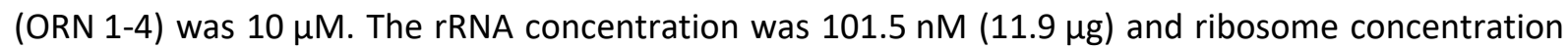
was $250 \mathrm{nM}$. The enzyme concentration was either $10 \mu \mathrm{M}$ or $16 \mu \mathrm{M}$ ALKBH5 $5_{66-292}$.

All assays with ORNs or rRNA were incubated at $37^{\circ} \mathrm{C}$ for $1 \mathrm{~h}$. Assays with native ribosomes were incubated in a Thermomixer for $4 \mathrm{~h}$ at $37^{\circ} \mathrm{C}$ and $1000 \mathrm{rpm}$. Assays with rRNA and native ribosomes were immediately stored at $-20^{\circ} \mathrm{C}$ for further RNA extraction. Every assay with synthetic RNA oligonucleotides was directly desalted (up to $30 \mathrm{~min}$ ) on a Merck Millipore MF ${ }^{\mathrm{TM}}$ VSWP-membrane $(0.025 \mu \mathrm{M})$ for an analysis by matrix-assisted laser desorption ionization (MALDI) mass spectrometry. A 3-Hydroxypicolinic acid (3-HPA) matrix was used. The native ribosomes and rRNA extraction from the assays was done with the Monarch ${ }^{\circledR}$ Total RNA Miniprep Kit by NEB. 
A) 5'-G-G-m $^{6} \mathrm{~A}-\mathrm{C}-\mathrm{U}-3^{\prime}$ (ORN-1)
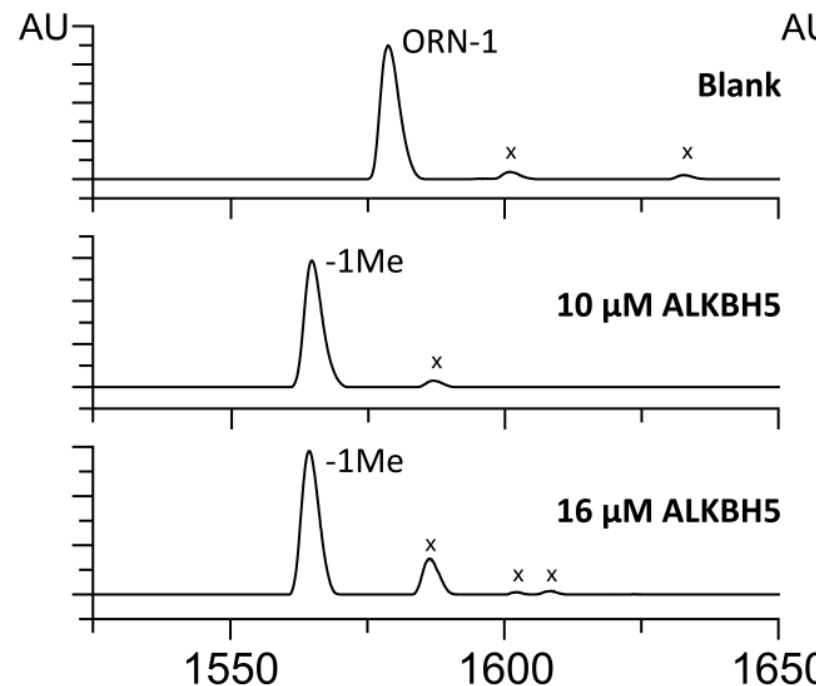

B) $5^{\prime}-G-U-G-m^{6} A-m^{6} A-C-U-U-3^{\prime}$ (ORN-2)
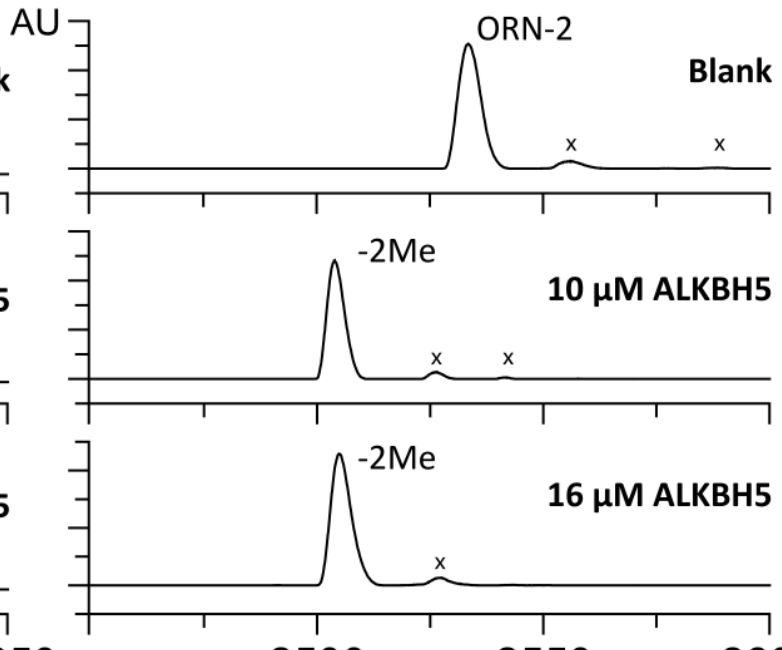

Supplementary Figure 2 (A and B) MALDI-ToF spectra of ORN-1 and ORN-2 and their demethylation products (-xMe) at different concentrations of ALKBH566-292. The sodium signals in the spectra are marked with an " $x$ ".

\section{Analytical methods}

\section{RNA digestion}

$1.0 \mu \mathrm{g}$ of RNA in $35 \mu \mathrm{L} \mathrm{H} \mathrm{H}_{2} \mathrm{O}$ were digested as follows: An aqueous solution $(7.5 \mu \mathrm{L})$ of $480 \mu \mathrm{M} \mathrm{ZnSO} \mathrm{Z}_{4}$, containing 18.4 U nuclease S1 (Aspergillus oryzae, Sigma-Aldrich), $5 \cup$ Antarctic phosphatase (NEB) and specific amounts of labelled internal standards $\left(\left[D_{3}\right]-m^{6}{ }_{2} A,\left[D_{3}\right]-m^{6} A\right)$ were added, and the mixture was incubated at $37^{\circ} \mathrm{C}$ for $2 \mathrm{~h}$. After addition of $7.5 \mu \mathrm{L}$ of a $520 \mu \mathrm{M}[\mathrm{Na}]_{2}$-EDTA solution, containing $0.15 \mathrm{U}$ snake venom phosphodiesterase I (Crotalus adamanteus, USB corporation), the sample was incubated for $2 \mathrm{~h}$ at $37^{\circ} \mathrm{C}$ and then stored at $-20^{\circ} \mathrm{C}$. Prior to UHPLC-MS/MS analysis, samples were filtered by using an AcroPrep Advance 96 filter plate $0.2 \mu \mathrm{m}$ Supor (Pall Life Sciences).

\section{UHPLC/MS-MS analysis of RNA samples.}

Quantitative UHPLC-MS/MS analysis of digested RNA samples was performed using an Agilent 1290 UHPLC system equipped with a UV detector and an Agilent 6490 triple quadrupole mass spectrometer. For exact quantification of $\mathrm{m}^{6} \mathrm{~A}$ and $\mathrm{m}^{6} \mathrm{~A}$ internal quantification with the stable isotope dilution technique was developed (Supplementary Fig. 2 and Supplementary Tab. 2 and 3). The canonical nucleosides (C, U, G, A) were measured and quantified with the UV-detector (Supplementary Tab. 3). The source-dependent parameters were as follows: gas temperature $80^{\circ} \mathrm{C}$, gas flow $15 \mathrm{~L} / \mathrm{min}\left(\mathrm{N}_{2}\right)$, nebulizer $30 \mathrm{psi}$, sheath gas heater $275^{\circ} \mathrm{C}$, sheath gas flow $11 \mathrm{~L} / \mathrm{min}\left(\mathrm{N}_{2}\right)$, capillary voltage $2,500 \mathrm{~V}$ in the positive ion mode and nozzle voltage $500 \mathrm{~V}$. The fragmentor voltage was $380 \mathrm{~V}$. Delta EMV was set to 500 (positive mode). Compound-dependent parameters are summarized in Supplementary Table 1. Chromatography was performed by a Poroshell 120 SB-C8 column (Agilent, $2.7 \mu \mathrm{m}, 2.1 \mathrm{~mm} \times 150 \mathrm{~mm}$ ) 
at $35{ }^{\circ} \mathrm{C}$ using a gradient of water and $\mathrm{MeCN}$, each containing $0.0075 \%(\mathrm{v} / \mathrm{v})$ formic acid, at a flow rate of $0.35 \mathrm{~mL} / \mathrm{min}: 0 \rightarrow 6 \mathrm{~min} ; 0 \rightarrow 6.0 \%$ (v/v) MeCN; $6 \rightarrow 7 \mathrm{~min} ; 6.0 \rightarrow 40 \% \mathrm{MeCN} ; 7 \rightarrow 10.8 \mathrm{~min} ; 40 \rightarrow 80 \%$ $\mathrm{MeCN} ; 10.8 \rightarrow 12.50 \mathrm{~min} ; 80 \% \mathrm{MeCN} ; 12,50 \rightarrow 13.50 \mathrm{~min} ; 80 \rightarrow 0 \% \mathrm{MeCN} ; 13.5 \rightarrow 15 \mathrm{~min} ; 0 \% \mathrm{MeCN}$. The effluent up to $1.1 \mathrm{~min}$ and after $14 \mathrm{~min}$ was diverted to waste by a Valco valve. The autosampler was cooled to $4{ }^{\circ} \mathrm{C}$. The injection volume was amounted to $39 \mu \mathrm{L}$.

\section{Determination of extinction coefficients}

For the following absolute internal quantification of nucleosides the exact concentration of the isotopically labeled internal standards needs to be known. In order to measure the concentrations one needs to determine the extinction coefficients first. For this determination, $\mathrm{m}^{6} \mathrm{~A}$ and $\mathrm{m}^{6} \mathrm{~A}$ were diluted in $\mathrm{D}_{2} \mathrm{O}$ as well as the reference nucleoside $\mathrm{U}$. The absorbance of all three solutions were measured as technical quintuplets on the NanoDrop 1000 Spectrophotometer for the $\lambda_{\max }$ of each nucleoside. Subsequently, a 1:1 mixture of $\mathrm{m}^{6} \mathrm{~A}$ and $\mathrm{U}$ as well as $\mathrm{m}^{6}{ }_{2} \mathrm{~A}$ and $\mathrm{U}$ was prepared, each mixture as a technical triplicate. Following ${ }^{1} \mathrm{H}-\mathrm{NMR}$ measurements of these mixtures resulted in specific ratios of the amount $n\left(m^{6} A\right)$ to the amount $n(U)$, respectively $n\left(m^{6}{ }_{2} A\right)$ to $n(U) .{ }^{1} H$-NMR spectra were recorded on Bruker Avance III HD $800 \mathrm{MHz}$. By applying the Beer-Lambert law one can calculate the actual concentration $c(U)$ solution with the literature known extinction coefficient $\left(\varepsilon_{\lambda}\right)$. With the ratio of $n$ $(U)$ to $n\left(m^{6} A\right)$, respectively $n(U)$ to $n\left(m^{6} A\right)$, one can calculate the concentrations $c\left(m^{6} A\right)$ and $c\left(m^{6} A\right)$ in each solution. Applying again the Beer-Lambert law results in the desired extinction coefficients of the two nucleosides $\varepsilon_{\lambda}\left(m^{6} A\right)$ and $\varepsilon_{\lambda}\left(m^{6} A\right)$ at a specific wavelength $\lambda$ (see Supplementary Table 1 ).

\section{Quantification of nucleosides}

In order to obtain the internal calibration curves for exact quantification, each standard, namely $\left[D_{3}\right]-m^{6} A$ and $\left[D_{3}\right]-m^{6}{ }_{2} A$ was analyzed in comparison to the corresponding non-labelled nucleoside with constant concentration. Technical triplicates were measured and the linear regression was applied using Origin ${ }^{\circledast} 6.0$ (Microcal ${ }^{\mathrm{TM}}$ ). Therefore, the ratio of the area under the curve of unlabeled nucleoside (A) to the labelled standard $\left(A^{*}\right)$ was plotted against the ratio of the amount of unlabeled nucleoside (n) to the labelled one ( $n^{*}$ ) (see Supplementary Fig. 2). In order to obtain the UV calibration curves for quantification of the canonical nucleosides, namely $C, U, G$ and $A$ were measured in a concentration series. For every nucleoside two different solutions were diluted with a dilution factor of two in order to get five different concentrations for every nucleoside, which were measured as technical triplicates. The UV area under the curve (A) was plotted against the amount of the nucleoside (n) (see Supplementary Tab. 3). Acceptable precision ( $<20 \%$ relative s.d. within each triplicate) and accuracy (80-120\%) was achieved for all calibration curves. The accuracy is calculated as the ratio of the measured to the calculated ratios of the areas $\left(A / A^{*}\right)$ under the curves in percent. The ratios of the areas $\left(A / A^{*}\right)$ can be calculated by using the linear equations for the corresponding ratio of amount 
$\left(n / n^{*}\right)$. The lower limit of detection was defined as the detected amount, which is three times higher than the blank response (LOD). The lower limit of detection (LLOQ) and the upper limit of detection (ULOQ) are the lowest, respectively the highest amount ( $n$ ) and ratio of the amounts (A/A*) fulfilling the requirements of the corresponding linear equation.

\section{LC-MS analysis of ORN-4}

The analysis of the ORN-4 assay with $16 \mu \mathrm{M}$ ALKBH5 ${ }_{66-292}$ were analyzed by LC-ESI-MS on a Thermo Finnigan LTQ Orbitrap XL and were chromatographed by a Dionex Ultimate 3000 HPLC system with a flow of $0.15 \mathrm{~mL} / \mathrm{min}$ over a Phenomenex Synergi ${ }^{\mathrm{TM}} 2.5 \mu \mathrm{m}$ Fusion-RP $100 \AA \AA \mathrm{C} 18$ column. The column temperature was maintained at $30^{\circ} \mathrm{C}$. The used eluting buffers were buffer $\mathrm{A}\left(10 \mathrm{mM} \mathrm{NH}_{4} \mathrm{OAc}\right.$ in $\mathrm{H} 2 \mathrm{O}$ $(\mathrm{pH} 7)$ ) and buffer $\mathrm{B}(\mathrm{MeCN})$. The elution was monitored at $260 \mathrm{~nm}$ (Dionex Ultimate 3000 Diode Array Detector). The chromatographic eluent was directly injected into the ion source without prior splitting. Ions were scanned by use of a positive polarity mode over a full-scan range of $\mathrm{m} / \mathrm{z}$ 120-2000 with a resolution of 30000 .

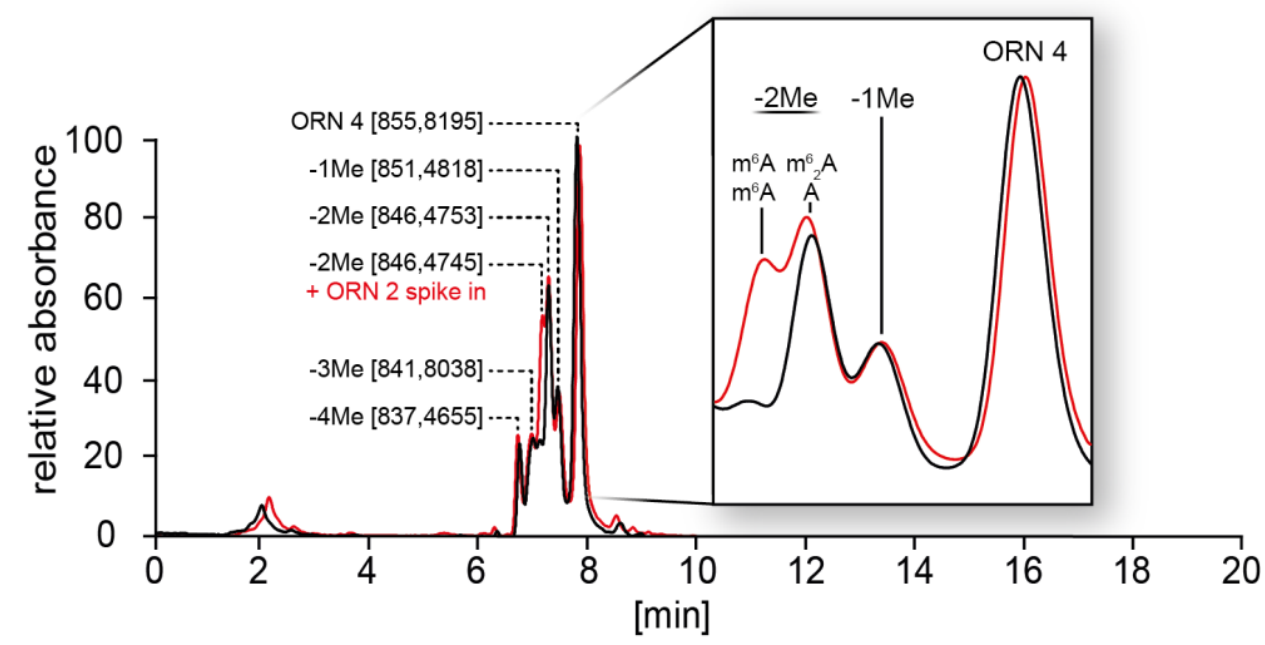

Supplementary Figure $3 \mathrm{HPL}$ chromatogram of the incubation of ORN-4 with $16 \mu \mathrm{M}$ ALKBH566-292 (black line) and with a spike in of ORN-2 (red line). The measured mass of the different species is shown in square brackets $\left([\mathrm{M}+3 \mathrm{H}]^{+3}\right)$ 


\section{Supplementary Tables}

Supplementary Table 1 Determined extinction coefficients for $m^{6} A$ and $m^{6} A$.

\begin{tabular}{c|cc} 
compound & $\varepsilon_{\lambda \max }\left(\lambda_{\max }\right)\left[L \cdot \mathrm{mol}^{-1} \cdot \mathrm{cm}^{-1}\right]$ & $\varepsilon_{\lambda=260 \mathrm{~nm}}\left[L \cdot \mathrm{mol}^{-1} \cdot \mathrm{cm}^{-1}\right]$ \\
\hline $\mathrm{m}^{6} \mathrm{~A}$ & $15474(267 \mathrm{~nm})$ & - \\
$\mathrm{m}^{6}{ }^{2} \mathrm{~A}$ & $19047(274 \mathrm{~nm})$ & 12623
\end{tabular}

Supplementary Table 2 Compound-dependent LC-MS/MS-parameters used for the analysis of RNA. CE: collision energy, CAV: collision cell accelerator voltage, EMV: electron multiplier voltage. The nucleosides were analyzed in the positive $([\mathrm{M}+\mathrm{H})]^{+}$species) ion selected reaction monitoring mode (SRM).

\begin{tabular}{|c|c|c|c|c|c|c|c|c|}
\hline compound & $\begin{array}{c}\text { Precursor } \\
\text { ion }(\mathrm{m} / \mathrm{z})\end{array}$ & $\begin{array}{c}\text { MS1 } \\
\text { Resolution }\end{array}$ & $\begin{array}{c}\text { Product } \\
\text { lon }(\mathrm{m} / \mathrm{z})\end{array}$ & $\begin{array}{c}\text { MS2 } \\
\text { Resolution }\end{array}$ & $\begin{array}{c}\text { Dwell } \\
\text { time } \\
{[\mathrm{ms}]}\end{array}$ & $\begin{array}{c}\text { CE } \\
(\mathrm{V})\end{array}$ & $\begin{array}{c}\text { CAV } \\
(\mathrm{V})\end{array}$ & Polarity \\
\hline \multicolumn{7}{|c|}{ Time segment 2.4-14 min } \\
\hline$\left[\mathrm{D}_{3}\right]-\mathrm{m}^{6}{ }_{2} \mathrm{~A}$ & 299.15 & Wide & 167.11 & Wide & 60 & 2 & 5 & Positive \\
\hline $\mathrm{m}^{6}{ }_{2} \mathrm{~A}$ & 296.14 & Wide & 164.11 & Wide & 60 & 2 & 5 & Positive \\
\hline$\left[\mathrm{D}_{3}\right]-\mathrm{m}^{6} \mathrm{~A}$ & 285.14 & Wide & 153.10 & Wide & 60 & 2 & 5 & Positive \\
\hline $\mathrm{m}^{6} \mathrm{~A}$ & 282.12 & Wide & 150.08 & Wide & 60 & 2 & 5 & Positive \\
\hline
\end{tabular}

Supplementary Table 3 Compound-dependent LC-MS/MS ranges of the corresponding linear equations.

\begin{tabular}{c|cccc} 
compound & $\mathrm{n}$ (ULOQ) [pmol] & $\mathrm{n}$ (LLOQ) [pmol] & $\mathrm{A} / \mathrm{A}^{*}$ (ULOQ) & $\mathrm{A} / \mathrm{A}^{*}$ (LLOQ) \\
\hline $\mathrm{m}^{6} \mathrm{~A}$ & 3.104 & 0.049 & 4.13 & 0.040 \\
$\mathrm{~m}^{6} \mathrm{~A}$ & 1.709 & 0.053 & 1.18 & 0.029
\end{tabular}



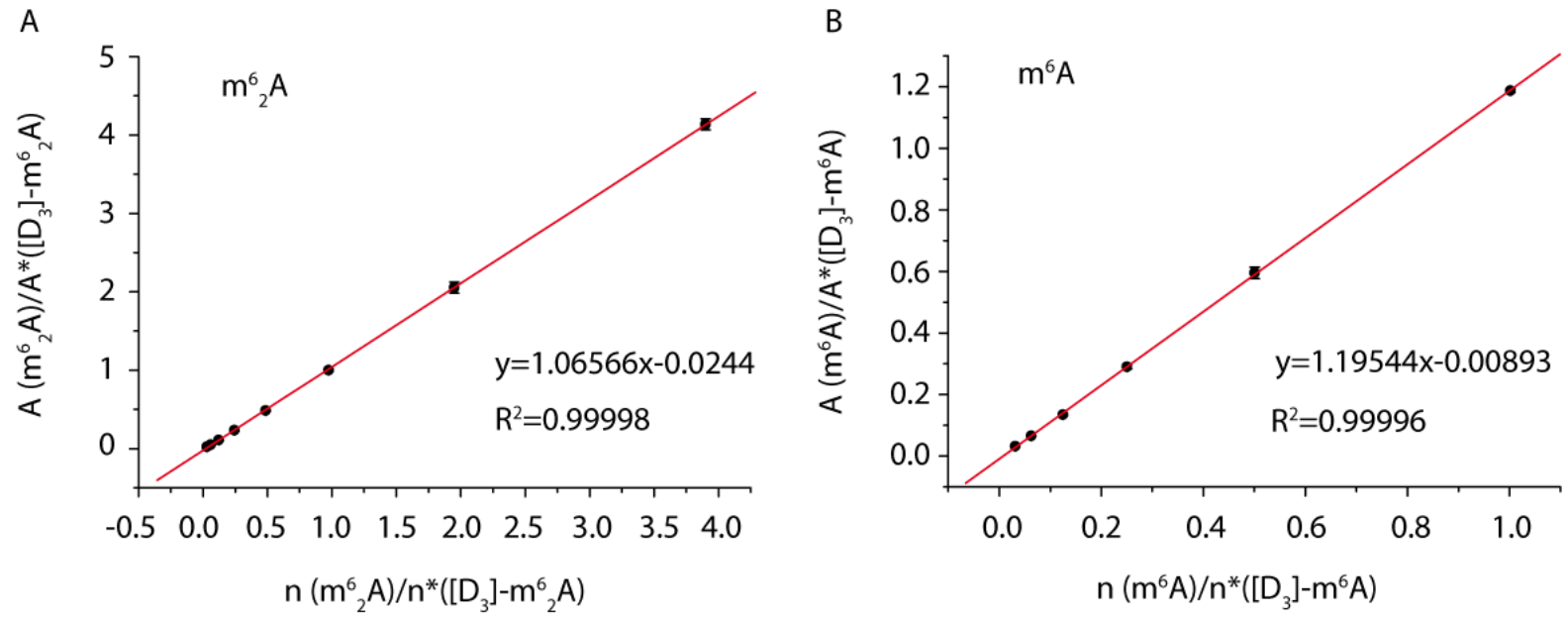

Supplementary Figure 4 Internal calibration curves for the exact quantification of $m^{6}{ }_{2} A(A)$ and $m^{6} A(B)$ with the corresponding linear equation and coefficient of determination.

Supplementary Table 4 Compound-dependent UV ranges and the corresponding linear equations of the canonical nucleosides.

\begin{tabular}{c|ccc} 
compound & linear regression & $\mathrm{n}$ (ULOQ) [pmol] & $\mathrm{n}$ (LLOQ) [pmol] \\
\hline C & $\mathrm{y}=0.28955 \mathrm{x}+0.17515$ & 791 & 24.7 \\
U & $\mathrm{y}=0.45953 \mathrm{x}-0.34086$ & 792 & 24.7 \\
G & $\mathrm{y}=0.56985 \mathrm{x}-0.91256$ & 792 & 24.7 \\
A & $\mathrm{y}=0.62408 \mathrm{x}-0.10334$ & 659 & 20.6
\end{tabular}
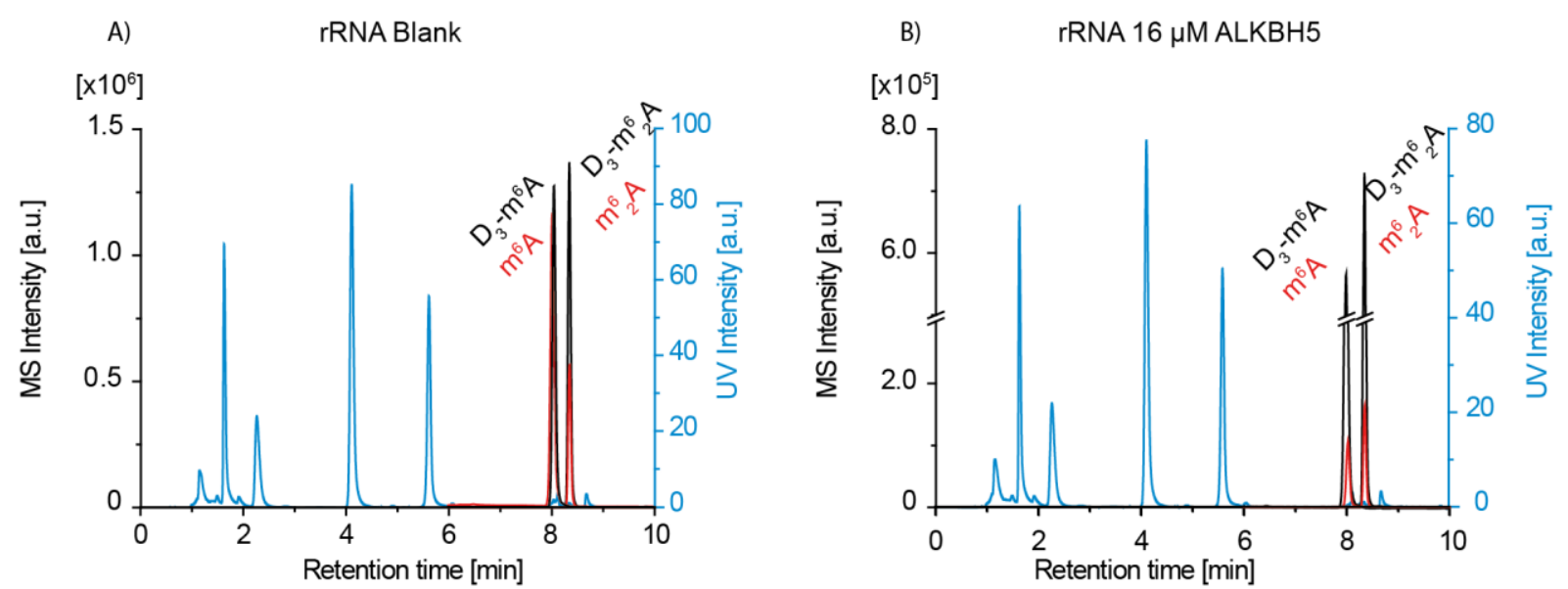

Supplementary Figure 5 UV Chromatogram (blue) and MS trace (red: natural modification; black: isotopically labelled standard) of rRNA are shown, upon incubation with $16 \mu \mathrm{M}$ ALKBH566-292 (B) and without ALKBH566-292 (A). 


\section{Literature}

1. R. R. Edupuganti, S. Geiger, R. G. H. Lindeboom, H. Shi, P. J. Hsu, Z. Lu, S.-Y. Wang, M. P. A. Baltissen, P. W. T. C. Jansen, M. Rossa, M. Müller, H. G. Stunnenberg, C. He, T. Carell and M. Vermeulen, Nat. Struct. Mol. Biol., 2017, 24, 870-878.

2. C. Höbartner, C. Kreutz, E. Flecker, E. Ottenschläger, W. Pils, K. Grubmayr and R. Micura, Monatsh. Chem., 2003, 134, 851-873. 